92

\title{
Inovação Pedagógica com Tecnologia: \\ mundos imersivos e agentes conversacionais
}

\author{
Liane Margarida Rockenbach Tarouco \\ Programa de Pós-Graduação em Informática na Educação \\ Centro Interdisciplinar de Novas Tecnologias na Educação \\ UFRGS
}

\section{Resumo}

Este artigo aborda a evolução do uso da tecnologia com recurso de inovação pedagógica aprofundando no uso de mundos imersivos como recurso para a criação de laboratórios virtuais. A partir da evolução do uso de tecnologia como suporte para a aprendizagem, são apresentadas soluções que inicialmente usaram CAI - Computer Aided Instruction e evoluíram para a implantação de laboratórios virtuais imersivos e uso de Internet das Coisas.

Palavras chave: tecnologia na educação, mundos virtuais, laboratórios virtuais, Internet das Coisas

\begin{abstract}
This paper discusses the evolution of the use of technology with pedagogical innovation, deepening the use of immersive worlds as a resource for the creation of virtual laboratories. From the evolution of the use of technology as a support for learning, are presented solutions that initially used CAI - Computer Aided Instruction and evolved to the implementation of immersive virtual laboratories and use of Internet of Things.
\end{abstract}

Keywords: technology in education, virtual worlds, virtual laboratories, Internet of Things

\section{Revoluções da aprendizagem}

Inicialmente cabe comentar algo sobre a evolução da tecnologia como forma de aprimorar a educação. Isto ser feito a partir de um breve um histórico sobre como chegamos ao estágio atual em termos de inovação pedagógica com tecnologia. É possível identificar 3 revoluções na aprendizagem em função da tecnologia usada que iniciou com o domínio da escrita.

Antropólogos afirmam que uma das necessidades fundamentais do ser comunicação humano é a transmissão da cultura de geração para geração. Nas primeiras comunidades humanas a família era a unidade primária para este propósito. Com o advento da escrita e da manutenção de registros, pequenas escolas surgiram para treinar um grupo seleto de cada comunidade com vistas a adquirir as habilidades necessárias para manter e desenvolver tais registros. Essas escolas diferenciadas constituíam o início da primeira revolução educacional (Cummings 2003).

- $1^{\text {a }}$ Revolução - escrita manual de livros 
A educação até então era realizada apenas pela interação presencial dos alunos com os sábios da época, como Sócrates. Como ele gostava de fazer suas preleções caminhando, os alunos o seguiam para não perder uma palavra. Nesta época, preliminar ao uso de qualquer tecnologia na educação, o conhecimento era limitado aos poucos que tinham recursos para participar dessas sessões com os detentores do saber. Os livros que existiam eram escritos à mão pelos monges e o acesso aos mesmos era bastante limitado. Nesta época o conhecimento ainda estava muito circunscrito, muito fechado.

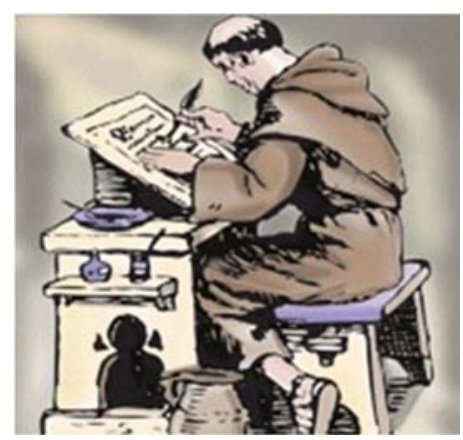

Figura 1: A produção manual de livros pelos monges

Mas mesmo sendo raros e escassos, os livros liberaram o estudante da necessidade da interação face a face com sábios e outras fontes humana de conhecimento, erudição e informação. O saber passou a estar disponível em qualquer lugar, a qualquer momento. Os livros representaram, nesta fase, a essência da la revolução na aprendizagem e constituíram uma relevante tecnologia, falando em termos mais amplos.

- $\quad 2^{\mathrm{a}}$ Revolução - a imprensa por tipos móveis

Assim como a invenção da escrita facilitou a primeira revolução da educação invenção da imprensa escrita preparou o cenário para a segunda revolução educacional. Até aquele momento, no Ocidente, a igreja era o principal repositório da bíblia e da maioria de outros livros importantes. Os monges copiavam laboriosamente esses livros nos mosteiros e estes eram distribuídos com moderação para várias instituições religiosas, incluindo as escolas religiosas e paroquiais. Apenas uma pequena parcela do público em geral, aqueles com riqueza, fé e um interesse em aprendizagem era capaz de ter bibliotecas privadas (Cummings 2003)

Mas a partir do final do século XV, avanços importantes foram feitos com a impressão mecânica de livros. Talvez o mais conhecido caso seja a bíblia de Gutenberg em 1455. A tecnologia nesta fase foi o desenvolvimento de tipos móveis quando Gutenberg criou os tipos móveis de metal ( ou prensa de tipos móveis), construindo a primeira impressora. Isso facilitou a impressão dos livros o que tornou sua produção em série possível e reduziu o custo.

Daquele dia em diante, a Igreja perdeu seu monopólio do livro sagrado. Novos movimentos religiosos surgiram defendendo o direito de crentes individuais terem acesso direto à palavra divina. Uma demanda foi criada para a Bíblia e para a alfabetização essencial para poder ler este grande livro. A Reforma se espalhou pela Europa, semeando as sementes da revolução moderna da educação. Enquanto o maior impulso para a mudança foi a demanda por alfabetização em massa, a revolução teve outras decorrências incluindo uma ampliação dos valores educacionais no currículo para colocar pelo menos tanta ênfase na reverência a Deus quanto um aumento na ênfase da assuntos seculares como matemática e ciência. 
Veio então a 2a revolução na educação em função de uma nova tecnologia, a dos livros impressos cujo custo, muito mais reduzido, tornou seu uso acessível para uma população maior. Um exemplo de livro desta época foi o escrito por Abraham Rockenbach (um possível decavô meu), que era professor na Universidade de Frankfurt (am Oder) por volta de 1600. Ele era professor de Grego, Matemática e Ciências Jurídicas. Ele produziu 23 livros ou textos menores aos quais se pode ter acesso ainda hoje pois estão depositados em bibliotecas de algumas universidades. O livro De cometis tractatvs novvs methodicvs, escrito por Abraham Rockenbach (1611), por exemplo, está disponível na biblioteca da Universidade de Cornell, em Ithaca-NY.
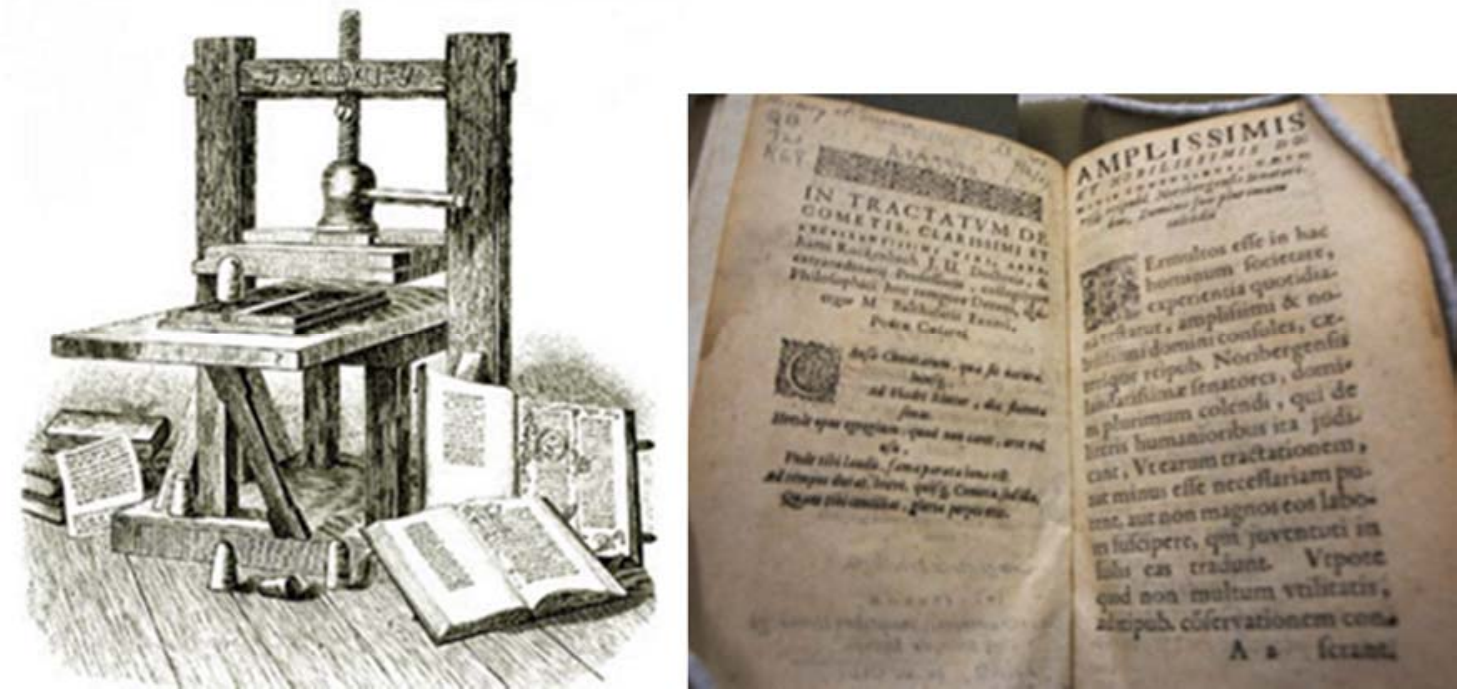

Figura 2: Desenvolvimento dos tipos móveis para impressão de livros

- $\quad 3^{\mathrm{a}}$ Revolução - computadores

O advento dos computadores permitiu estabelecer uma terceira revolução na aprendizagem pois possibilitam adaptar a sequência e do tipo de operações que executam em função das condições do momento. Isto significa, na educação, a possibilidade de individualização do processo de aprendizagem, adaptar o conteúdo, a sequência, o tipo de atividades, o seu grau de dificuldade e granularidade do material preparado para apoiar o trabalho dos alunos, de acordo com suas necessidades. Possibilitou usar recursos de adaptação e interatividade, bem como apresentar recursos multimídia sob demanda, além de permitir regular a intensidade da aprendizagem variando a quantidade de questões apresentadas, respondidas, formuladas em função das características dos alunos.

\subsection{Evolução dos computadores na educação}

Diversas tecnologias em termos de computadores permitiram o desenvolvimento de novas estratégias pedagógicas.

a) Programmed Instruction, Learning, or Teaching (PILOT) (Collon 1984)

PILOT foi uma linguagem de programação simples, desenvolvida nos anos 60 que permitia criar programas e representou uma incursão preliminar na tecnologia da instrução assistida por computador. Havia implementação em computadores de grande porte com acesso por terminais remotos ou para computadores pessoais como o TRS-80 
Color Computer da RadioShack (Figura 3) . O PILOT foi desenvolvido por John Amsden Starkweather, professor de psicologia do centro médico da Universidade da Califórnia em San Francisco. Em 1962, ele desenvolveu uma linguagem simples para automatizar testes de aprendizado chamados Computest. A partir de 1968, ele desenvolveu um projeto subsequente chamado PILOT, para vários computadores da época.

Esta combinação, linguagem de programação fácil e computadores pessoais permitiu desenvolver material educacional digital interativo para crianças, usando um computador pessoal TRS-80 Color Computer da Radio Shack que era conectado a um monitor de TV conforme relatado por Tarouco (1981). O material instrucional que esta ferramenta permitia criar era constituído por material textual com explanações entremeadas de perguntas que deveriam ser respondidas pelos estudantes com correção imediata das respostas pelo programa e realimentação imediata para o usuário. Isto permitia criar um material para o que se convencionou denominar CAI - Computer Aided Instruction. Esta abordagem se caracterizava por proporcionar ao aluno algumas funcionalidades básicas: ritmo próprio (o aluno avança de acordo com o tempo que necessita para trabalhar, pensar e responder às questões formuladas), resposta ativa (a necessidade de uma reação ativa do estudante aumenta a motivação em oposição a uma participação meramente passiva que tende a desestimular a cansar mais facilmente o estudante), realimentação imediata (que aumenta a atenção pois oferece o resultado da avaliação da reação do estudante com rapidez e enseja novas tentativas, se desejado). A possibilidade de ir ajustando a sequência de etapas em função das respostas do estudante permite adaptar dinamicamente o material educacional às necessidades do estudante $o$ que otimiza o tempo despendido pelo aluno.

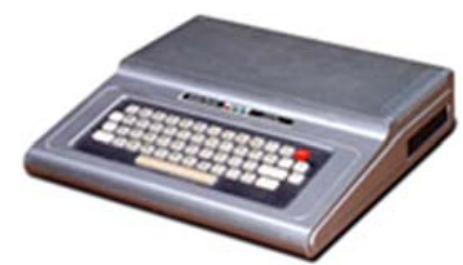

Figura 3 - TRS-80 Color Computer da RadioShack

\section{b) SISCAI - Sistema de Computer Aided Instruction - B6700 - DCAlgol}

Com o desenvolvimento e redução no custo dos computadores houve a disseminação no uso da estratégia de CAI - Computer Aided Instruction, uma técnica de autoaprendizagem, que pode ser offline ou online, envolvendo a interação do aluno com materiais instrucionais programados. A instrução assistida por computador (CAI) é uma técnica instrucional interativa na qual um computador é usado para apresentar o material instrucional e monitorar o aprendizado que ocorre. O CAI refere-se ao uso do computador como uma ferramenta para facilitar e melhorar a instrução. Os programas da CAI usam tutoriais, exercícios de treino e prática, simulação e abordagens de resolução de problemas para apresentar tópicos, e testam a compreensão do aluno.

Um exemplo deste tipo de uso na UFRGS foi a implantação de um sistema denominado SISCAI, implementado no mainframe Burroughs B-6700 (Klein 1981). A implantação deste sistema foi possível a partir de recursos recebidos no âmbito de um edital da universidade para apoiar projetos que visassem melhorar as condições de ensino 
e aprendizagem usando tecnologia. Com os recursos recebidos foi possível implantar uma sala de terminais para uso pelos alunos e foi desenvolvido um sistema para gerenciar a apresentação de conteúdos educacionais em forma de instrução programada multi ramificada. O sistema, implantado usando a linguagem DCALGOL, e o conteúdo inicial foi um curso de FORTRAN, a linguagem de programação que era ensinada aos alunos da Engenharia.

O resultado do experimento foi bastante interessante pois os alunos apreciavam poder substituir as aulas regulares por sessões interativas com o material educacional. $\mathrm{O}$ tempo despendido com todo o curso, quando ministrado pelo SISCAI foi em média 11 horas, contrastando com as 60 horas de aula expositiva do curso tradicional. $O$ desempenho dos alunos que fizeram o curso pelo sistema online foi ligeiramente superior ao dos alunos que trabalharam na forma tradicional, com aulas expositivas conforme relatado por Klein (1981). Uma das grandes vantagens desta abordagem foi a de que o aluno podia avançar tão rápido quanto desejasse ou se sentisse confiante para fazer. Nem precisava aguardar que o professor explicasse todos os detalhes com todos os exemplos, se já tivesse percebido o ponto em foco, e poderia, por outro lado, rever tantas vezes quantas quisesse, as explicações, caso não tivesse compreendido bem. Mas mesmo os que demoraram mais tempo no curso online, despenderam até 21 horas, ou seja, cerca de um terço do tempo do curso tradicional em sala de aula.

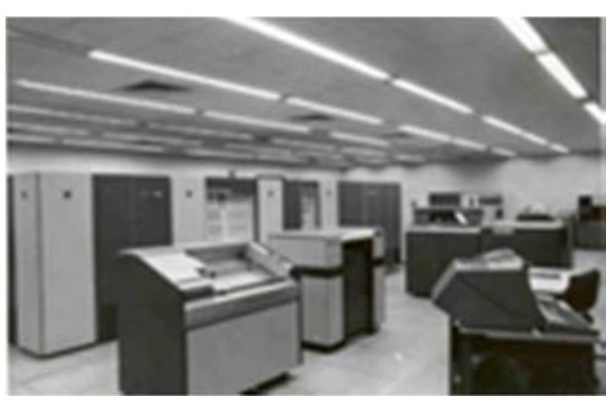

Figura 4 - Mainframe B6700 no CPD da UFRGS

c) CAIMI - Computer Aided Instruction para Microcomputadores - Basic

O surgimento dos microcomputadores ensejou uma maior disseminação do uso do computador como recurso educacional pois os computadores de grande porte tinham custo elevado e como o acesso aos mesmos necessitava de terminais remotos, a dificuldade e custo para conseguir a interligação destes tornavam proibitivo seu uso como recurso de aprendizagem. Linguagens de programação como o BASIC facilitam o desenvolvimento de software para CAI nestes equipamentos e o sistema antigo, SISCAI, foi transformado em 1982 para ser usado neste novo contexto, tendo recebido a designação de CAIMI. O conteúdo educacional passou a ser gerenciado no novo sistema e com o novo ambiente ficou facilitado o trabalho de manutenção do conteúdo (para fins de atualização do mesmo). Começou então uma fase de expansão do uso do CAIMI com conteúdo educacional sendo desenvolvido para áreas diversificadas, tais como escolas de segundo grau e ensino superior ou Informática Médica (Santarosa 1993).

d) Objetos de aprendizagem com animação

A CAI pode usar uma combinação de texto, gráficos, som e vídeo para aprimorar o processo de aprendizado tornando seu uso mais atraente e motivador. Com o advento RENOTE 
de ferramentas de autoria como Macromedia Flash tornou-se mais fácil, mesmo para pessoas sem formação em computação, a criação de animações, simulações e jogos sérios que tornaram o conteúdo educacional digital mais engajador para o estudante, aumentando sua motivação para permanecer mais tempo envolvido com o estudo do material educacional.

Mas esta tecnologia da Macromedia sofreu um processo de obsolescência forçada e diminuição no seu uso em decorrência de inseguranças inerentes ao uso do Flash aliado a motivações comerciais (disputa entre empresas e novas práticas comerciais da Adobe que adquiriu a Macromedia e incorporou o Flash ao Adobe Creative Suit). Como consequência, ocorreu uma drástica redução no uso da ferramenta de autoria Flash para criação de objetos de aprendizagem e os objetos de aprendizagem existentes, tais como os que o MEC coletou em seu BIOE - Banco Internacional de Objetos Educacionais, começaram a ficar obsoletos, por falta de manutenção e de portabilidade para uso em dispositivos móveis.

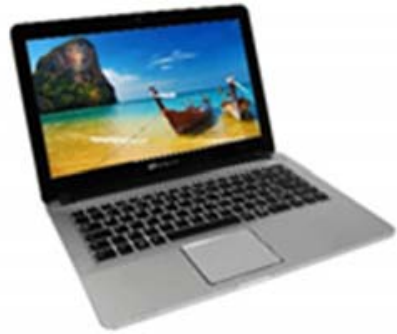

Figura 5: Conteúdo educacional digital multimídia com animação e interatividade

e) Uso de dispositivos móveis

Com o atual estágio de disseminação da tecnologia ocorreu uma mudança no perfil da população nascida na virada do milênio a qual passou a ser denominada de geração digital. A facilidade para usar de forma quase intuitiva os recursos digitais por esta geração levou a um nível de alfabetização digital bastante elevado. Um levantamento realizado e 2019 na UFRGS mostrou que 95,8 \% dos estudantes possui um PC ou notebook em casa. A amostra foi de 11859 estudantes. $72 \%$ dos estudantes possui celular com sistema Android e 23\% possui celular Iphone. Estas são as opções majoritárias. 49 $\%$ dos estudantes usa dispositivos móveis para atividades educacionais diariamente.

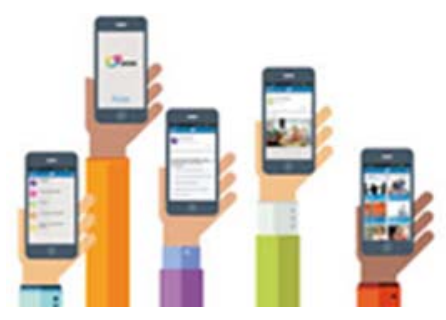

Figura 6: Uso de dispositivos móveis como recurso educacional

Esta realidade mostra que é necessário considerar novas estratégias em termos de uso da Tecnologia de Informação e Comunicação na Educação. Isto passa tanto pelo uso de aplicativos (apps) prontos que atualmente existem no mercado, tais como ferramentas de produtividade para comunicação, produção de textos e material multimídias ou aplicações específicas para uso educacional em escopos mais fechados tais como ensino de Ciências, Línguas etc..., laboratórios digitais virtuais entre outra.

Ferramentas de autoria recentemente desenvolvidas, tais como as construídas pelo MIT (Massachusetts Institute of Technology) usando linguagens de programação 
baseadas em blocos de programação visual abriram novas possibilidade em termos de envolver professores e alunos, sem formação em computação, na construção de conteúdos educacionais multimídia interativos. Estas ferramentas, como Scratch 2.0 (MIT 2009) e sua versão mais recente, Scratch 3.0, que permite o uso em tablets, além do MIT App Inventor (MIT 2019) que usando o mesmo paradigma de programação permite criar aplicativos para execução em ambiente de smartphone, abriram toda uma nova gama em termos de desenvolvimento de conteúdo educacional digital, multimídia, interativo, com a participação do usuário final (professor e aluno sem formação em computação).

\section{Tecnologias emergentes na educação}

Analisando os estudos de tendências em termos de tecnologias emergentes, a partir do relatório do Grupo Gardner (2018) é possível observar que alguma solução em termos de novas tecnologias tem previsão de uso na área educacional a curto, médio e longo prazo. Dentre as tecnologias que estão em fase de grande popularização no cenário empresarial, os assistentes virtuais ou agentes conversacionais estão encontrando espaço no contexto educacional. Agentes conversacionais têm sido desenvolvidos para apoiar a atividade educacional, especialmente em cursos desenvolvidos na modalidade de educação a distância. Tais agentes possibilitam uma interação textual, usando linguagem natural que possibilita ao aluno enviar perguntas sobre o conteúdo sendo trabalhado para elucidar dúvidas bem como como sobre a organização do curso (tarefas a serem entregues, datas etc...).

Outra tecnologia emergente em uso crescente no âmbito educacional é a da realidade virtual que permite implementar mundos virtuais nos quais se pode construir laboratórios virtuais que simulam laboratórios reais e possibilitam a realização de experimentos que de outro modo não seriam possíveis seja pela falta de laboratórios, custo, risco inerentes ao experimento etc...

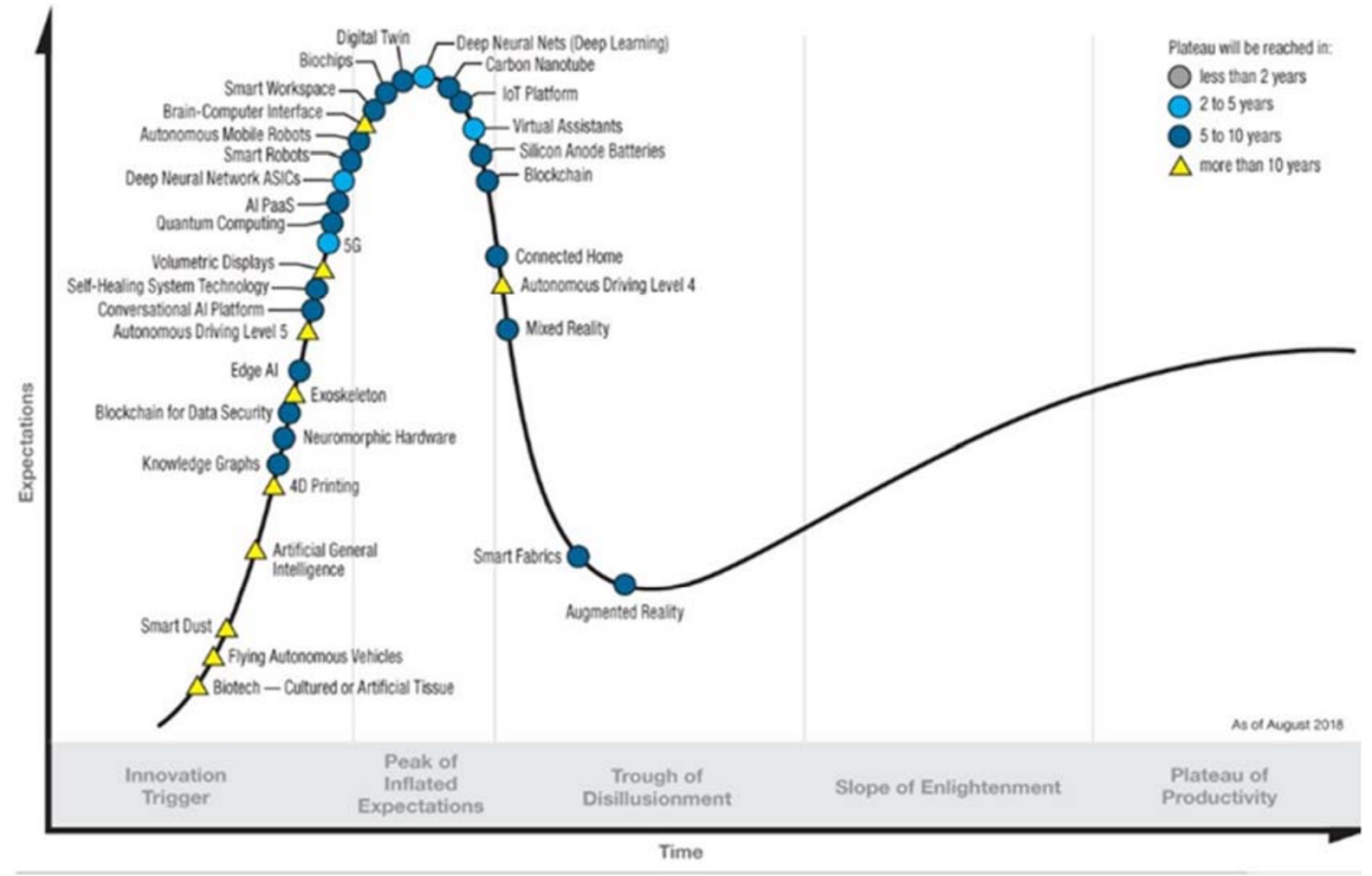


Figura 7: Hype Cycle for emerging tecgnologies - 2018 (Fonte; Gardner)

Mundos imersivos para a criação de laboratórios virtuais podem ser combinados com o recurso de agentes pedagógicos (agentes conversacionais) que também habitam o mundo virtual imersivo e podem interagir com o usuário, representado por seu avatar, para orientação, instigamento à reflexão sobre as atividades realizadas, responder questões etc...). A Figura 8 ilustra a implementação de um experimento em laboratório virtual construído no mundo virtual imersivo usando o ambiente de desenvolvimento Open Simulator. Open Simulator (2018) é um software livre, baseado no ambiente Second Life da Linden.

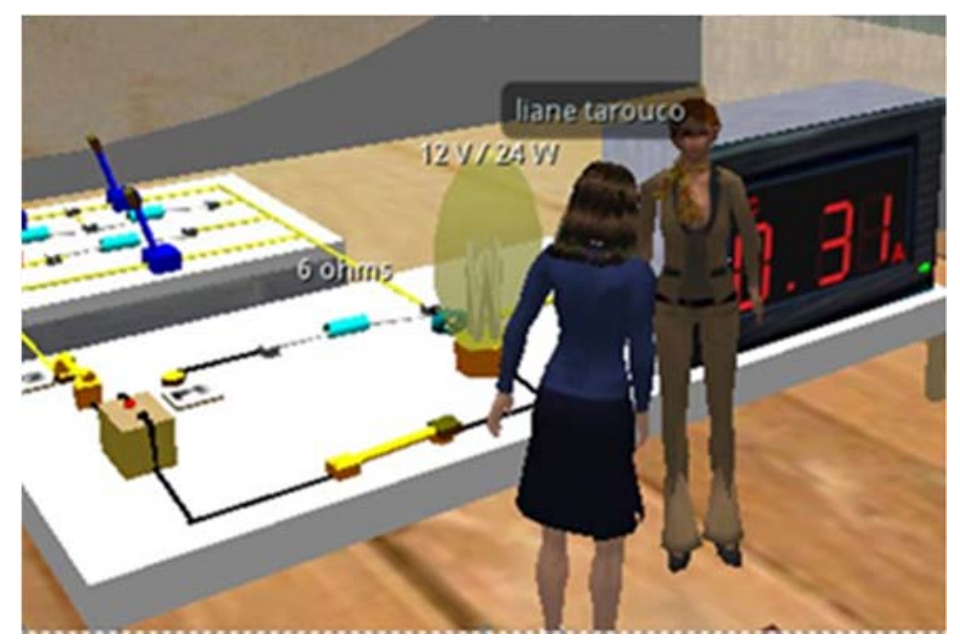

Figura 8 : Laboratório virtual

Além de permitir a simulação de experimentos, este ambiente também permite trazer para o laboratório virtual dados provenientes de sensores ou mesmo de câmeras reais, externos, que auxiliam a contextualizar melhor o experimento realizado.

O uso de ambientes imersivos para a criação de laboratórios virtuais é uma tendência sendo utilizada no mundo inteiro. Na Universidade de Harvard há um movimento denominado Immersive Education Initiative, da Harvard Graduate School of Education, coordenador por Dede, Midura e Metcalf (2009) que levou à criação de um ambiente denominado Ecomuve que contém toda a simulação de um ambiente conjunto de ambiente e que o aluno pode trabalhar virtualmente, percorrendo, inspecionando, coletando dados para analisar em busca de respostas para problemas a serem resolvidos. 


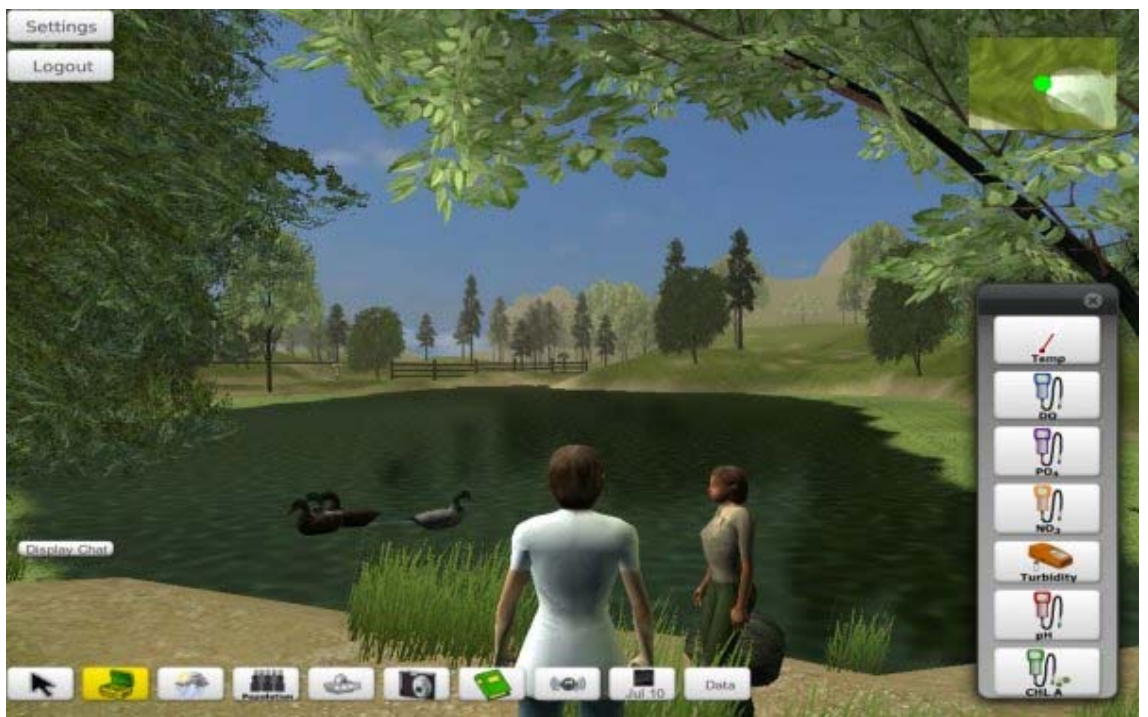

Figura 9: Ecomuve (http://ecomuve.gse.harvard.edu/)

Neste ambiente os estudantes são instigados a encontrar a causa para um problema de morte de peixes no lago. Eles precisam percorrer o ambiente, observar as condições em diversos dias, realizar medidas da qualidade da água, colocar dados em planilhas, observar, interagir com personagens virtuais que habitam o mundo virtual, como o responsável pela manutenção do campo de golfe, que usou produto para exterminar ervas daninhas. A partir desta informação os alunos devem analisar quando houve chuva no ambiente virtual que possa ter arrastado o herbicida para o lago, levando à morte dos peixes.

Um outro projeto usando mundo virtual imersivo foi o AVATAR - Ambiente Virtual de Aprendizagem e Trabalho Acadêmico Remoto, desenvolvido com recursos recebidos no âmbito do Edital CAPES/DED 03/2015 - Fomento à inovação para o desenvolvimento e aplicação de Tecnologias de Informação e Comunicação em Educação. O projeto AVATAR contemplou a implantação e configuração de um servidor baseado em software livre que permite criar um ambiente virtual imersivo para ensejar a realização de experimentos virtuais. No ambiente virtual imersivo criado os alunos encontram áreas ou salas onde tem a oportunidade de manipular artefatos e experimentos virtuais, desencadeando experiências simulando experimentos reais. Podem observar, anotar, intervir alterando configurações que regem o comportamento do experimento e interagir com outros usuários também representados por avatares para discussão da experiência e reflexão colaborativa.

O projeto AVATAR utiliza o software aberto Open Simulator para modelar ambientes imersivo visando a criação de laboratórios virtuais para o ensino de ciências entre outras aplicações. Este mundo virtual imersivo possibilita adição de recursos multimídia tais como slides, vídeos, animações, páginas web, além de objetos 3D que recebem programação (scripts) para exibir comportamentos dinâmicos quando o usuário, através de seu avatar interage com eles, clicando, enviando mensagens ou em outras condições (temporais ou de proximidade de elementos variados do ambiente). Objetos no ambiente podem ser configurados para se comportar como sensores. Tais sensores, ao detectar alguma movimentação, presença ou outra condição podem disparar mensagens que ativam comportamentos em outros objetos (Herpich et al 2017). 


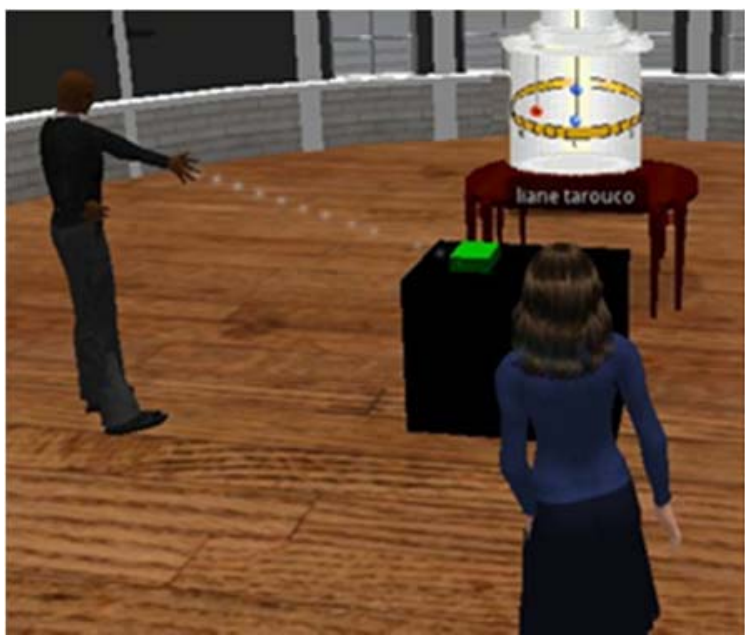

Figura 10 - Experimento no laboratório virtual

O ambiente permite o uso de entidades que se assemelham a um avatar, mas que não é controlado por um usuário em sim por um script. São denominados NPCs - Non Player Character. Estes NPCs podem ser configurados para estabelecer comunicação com um chatbot externo e passar a responder perguntas formuladas pelo usuário, consultando para isto a base de conhecimento que é utilizada pelo chatbot. A incorporação de cenários realistas e agentes (Non-Player Characters) controlados por roteiros permite enriquecer o ambiente criando mais oportunidades de interação.

A construção dos chatbots associados aos NPC usou a tecnologia desenvolvida no projeto ALICE - Artificial Linguistic Internet Computer Entity (2019) que também está disponível na forma de software livre. Esta solução disponibiliza uma máquina de inferência que trabalha usando informações de uma base de conhecimento construída com uma linguagem de marcação denominada AIML - Artificial Intelligence Markup Language. Existem várias implementações e no caso do projeto AVATAR foi usado o software livre Program D e também o Program O (free software). Uma intercomunicação entre OpenSim e o Chaterbot permite que as perguntas apresentadas pelo usuário no mundo virtual sejam encaminhadas para o chatbot e as respostas trazidas de volta para apresentação ao usuário. Diversos chatbots especializados em áreas do conhecimento diferentes foram implementados:

- HIGIA - Habitat Individual e Guia Interativa de Atitudes (Sgobbi, Tarouco, Reategui, 2017)

- ATENA - Agente Tutor para Ensino e Navegação no Ambiente (Herpich 201x)

- AGATA - Automatic Generation of AIML from Text Acquisition (Klarman 201x).

No caso do projeto HIGIA (Sgobbi, Tarouco, Reategui, 2017), o foco era a melhoria da atitude de usuário com sobrepeso buscando incentivar aumento na quantidade de exercitação diárias (caminhadas). Este projeto pesquisou o uso da teoria da autodeterminação como suporte para o projeto de um trabalho, calcado em mundos virtuais $3 \mathrm{D}$ e apoio de dispositivos atualmente disponíveis no contexto da Internet das Coisas, tais como o pedômetro. Adicionalmente foram combinadas tecnologias de agentes conversacionais, visando alcançar melhores resultados de autodeterminação por parte de pessoas com problemas de obesidade, que necessitam melhorar e/ou adquirir hábitos saudáveis. Foi implementado um sistema que tem com meta de ensejar 
aprendizagem de comportamentos na direção da promoção da saúde. O sistema delineado foi denominado HIGIA, como acrônimo de Habitat Individual e Guia Interativo de Atitudes (Sgobbi et al 2017). Foi utilizado um agente conversacional que interage com o sujeito da pesquisa dentro do mundo virtual, comentando os resultados derivados dos dispositivos externos, o que o incentiva a prosseguir e melhorar (Figura 11). Outra tecnologia que também foi combinada é a dos Non Player Character (NPC) que foram programados para exibir comportamentos dentro do mundo virtual (semelhante a avatares) que praticam exercícios apresentando muita disposição e alegria (figura 12). Durante sua participação no experimento, o participante deve permanecer o tempo todo com um pedômetro (medidor de movimento) em forma de presilha ou pulseira, o qual permite enviar os dados de atividades físicas do participante ao metaverso do Sistema Higia, que foi totalmente ambientado e caracterizado para apresentar dicas e/ou vídeos de bons hábitos nutricionais e especialmente um ambiente modulado para promover motivação para atividade física. Os dados que entram no Sistema, são analisados de forma a promover uma motivação extrínseca ao participante, com mensagens que atendam aos perfis de dados recebidos

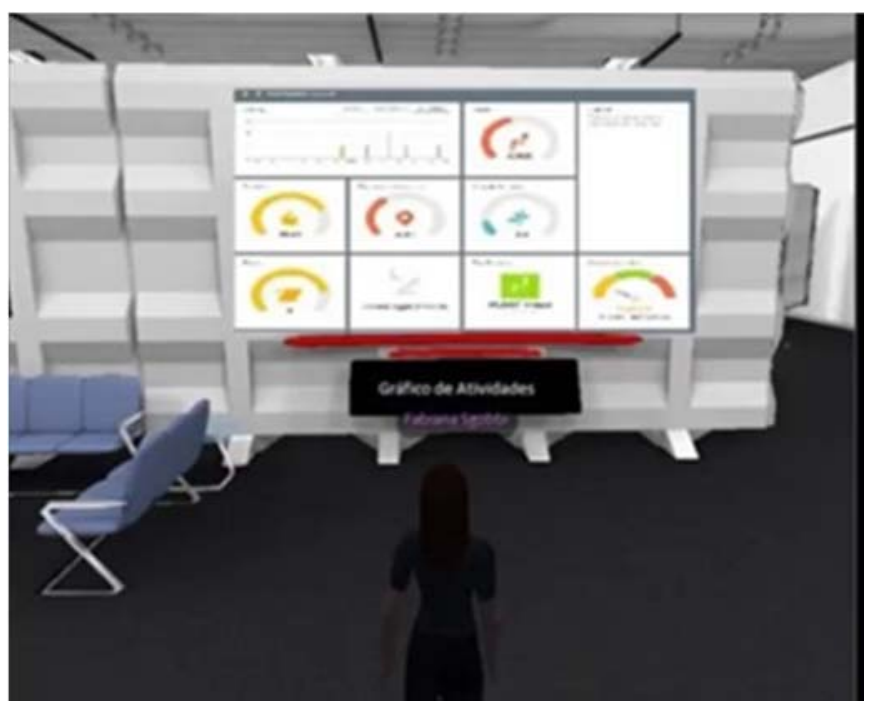

Figura 11: Apresentação de dados dos sensores no mundo imersivo

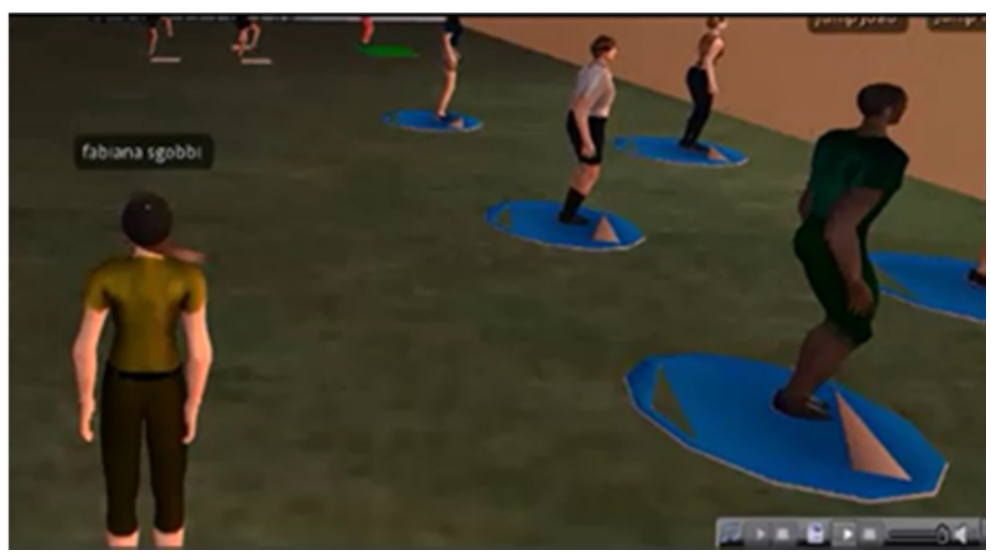

Figura 12: Academia virtual com NPCs

O ambiente permite adicionar todo um conjunto de recursos multimídia que podem ser exibidos na forma de painéis com páginas web, contendo animações, vídeos etc. Pode-se usar painéis com QRCode que o aluno pode ler com seu celular e exibir o 
recurso associado em seu smartphone, complementando assim as funcionalidades do mundo virtual.

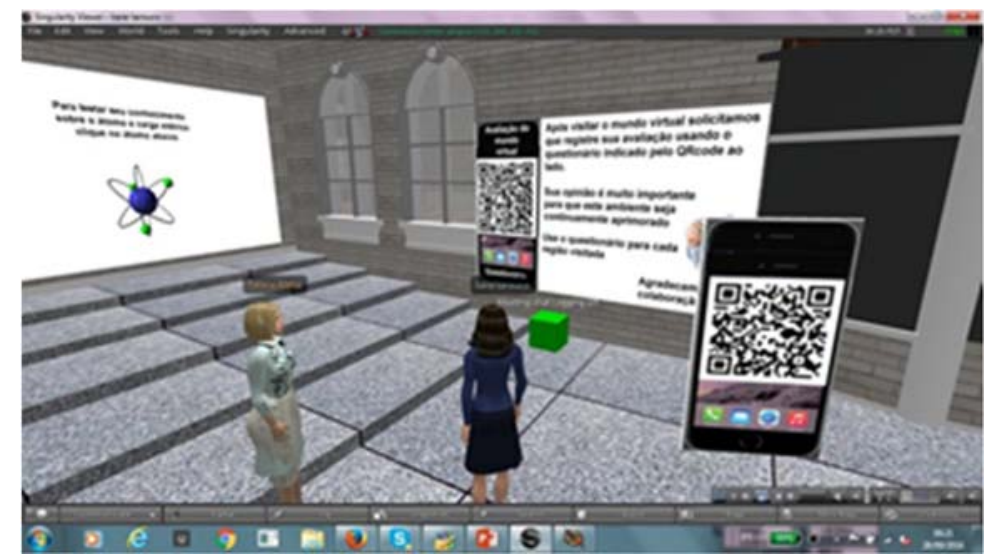

Figura 13: Recursos multimídia no mundo imersivo

Além desses recursos foi também utilizada a Realidade Aumentada para oferecer informações adicionais (animações, vídeos) sobre o comportamento dos objetos virtuais exibidos no laboratório virtual. O vídeo indicado no link abaixo mostra alguns resultados alcançados no projeto AVATAR.

Demonstração do ambiente AVATAR - Vídeo AVATAR

Daldarno (2010) destaca as seguintes propriedades ou dimensões de mundos imersivos: fidelidade representacional, imediatismo de controle e presença estimulam a participação ativa do estudante. Este autor também salienta que propriedades imersivas de um ambiente, tal como a fidelidade da representação, juntamente com os tipos de interatividade disponíveis no ambiente, levarão a um alto grau de imersão e, conseqüentemente, a um forte senso de presença.

Em decorrência destes estudos e com base na hipótese de que o realismo e a interatividade aumentam motivação e engajamento do estudante, foram incorporados ao projeto AVATAR algumas soluções visando aumentar o realismo. Scanners 3D foram usados para capturar objetos do mundo real e depois de tratar sua forma, usando editores de objetos $3 \mathrm{D}$, os mesmos puderam ser incorporados ao mundo virtual para uso nos laboratórios virtuais (Herpich et al 2017).

\section{Internet das Coisas}

Mais tarde foi iniciado um esforço na direção da Internet das Coisas. Uma das estratégias envolveu usar sensores para contar passos para ver o impacto nas pessoas que precisavam perder peso. acompanhar, conforme relatado no caso do projeto HIGIA. O laboratório foi construído no OpenSimulator e os dados capturados pelo relógio pedômetro eram transmitidos, via celular do usuário, para o site do fabricante, de onde eram recuperados e apresentados no mundo virtual, quando o usuário vinha realizar sua visita periódica. Os dados e estatísticas dele derivados eram explicados ao usuário no mundo virtual (figura 11) e o agente conversacional ficava também enviando mensagens de estímulo quando o usuário cumpria metas em termos de passos. Quando o usuário entrava no ambiente, via outras pessoas (avatares) fazendo exercícios (Figura 12). E não 
eram apenas pessoas com aparência fitness mas havia também pessoas com corpo menos esbelto e até um pouco desajeitados nos movimentos para que o usuário não se sentisse inferiorizado. O usuário recebia dicas e exemplos de exercícios que podia fazer e ele podia ver os avatares realizando os exercícios, tanto na academia como em ambientes externos. Se o usuário clicasse, por exemplo, numa esteira, ele passaria a ver seu avatar caminhando na esteira. Há estudos que mostram que se a pessoa enxergar seu avatar realizando algo ela sente-se mais motivada a repetir aquilo. Academias de fitness em New York estão usando este tipo de motivação para incentivar as pessoas a praticarem mais exercícios.

Atualmente está sendo investigado como todos estes estímulos afetam a motivação. Um dos recursos que estão sendo utilizados é um dispositivo de detecção de atividade cerebral, NeuroSky Mindwave Mobile que mede a emanação eletromagnética derivada da atividade cerebral na região frontal e estas medições são transmitidas para um smartphone e depois analisadas com um software que pode indicar momentos em que o sujeito da pesquisa estava com a atenção mais focada ou mais dispersa. Alguns resultados preliminares já obtidos mostraram que usando realidade aumentada para estudar determinado assunto levava a uma atenção mais focada do que se o mesmo assunto fosse estudado usando material textual ilustrado. Este tipo de recurso vai permitir avaliar o impacto de diferentes tipos de conteúdo e estratégias pedagógicas em termos de conseguir cativar a atenção dos estudantes.
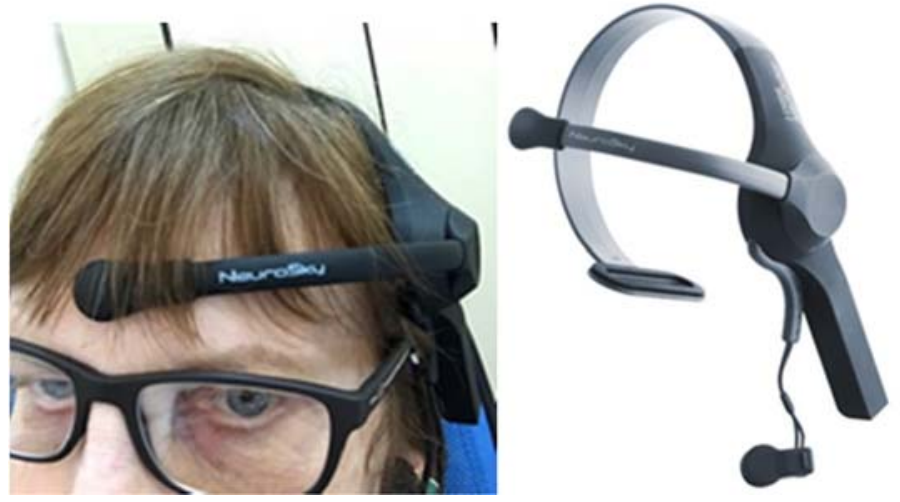

Figura 14 - NeuroSky Mindwave Mobile

Outro desenvolvimento recente é o do projeto ALERTA - Ambiente Lógico de Encaminhamento, Resposta e Tratamento de Avisos. (Tarouco, 2017). O projeto ALERTA propõe o uso combinado de sensoriamento participativo (Burke, Jeffrey 2006) e de rede de sensores. O sensoriamento participativo para gestão da infraestrutura envolve a participação dos usuários pois alguns tipos de problemas são difíceis de identificar por meio de técnicas tradicionais de sensoriamento automatizado que também tem questões de custo associados à sua instalação. Os usuários do campus podem auxiliar a gerenciar problemas tais como lixo jogado em local impróprio, buracos nas ruas, má conservação das calçadas, trânsito, pontos de alagamento, iluminação defeituosa, focos de dengue, recursos com defeito etc.

A nível de campus, a gestão colaborativa da infraestrutura pode incentivar o uso consciente de energia elétrica, água, relato de problemas percebidos pela comunidade em prédios e no campus de modo geral.

O uso de redes de sensores visa a monitorização da qualidade ambiental dos espaços de ensino existentes em relação à qualidade do ar interior, tal como mostrado nas figuras 15 e 16. O sistema ALERTA também inclui um módulo para receber avisos 
gerados a partir da coleta e análise de dados provenientes de sensores ambientais. Os sensores inicialmente implementados (Figura 15) visam avaliar a qualidade ambiental dos espaços de ensino existentes em relação à qualidade do ar interior, que é uma necessidade gerada pelo grande período em que estudantes permanecem em um ambiente confinado face ao impacto da qualidade do ar na cognição e aprendizagem. Este problema já tem sido amplamente estudado e a Organização Mundial da Saúde inclusive definiu a Síndrome do Prédio Doente "um conjunto de doenças causadas ou estimuladas pela poluição do ar em espaços fechados"

Há estudos que apontam associação entre a redução do rendimento escolar com baixas taxas de ventilação ou altas concentrações de CO2. Níveis de concentração de CO2 maiores do que 1500 ppm por exemplo geram cognição reduzida (Bakó-Biró 2012).

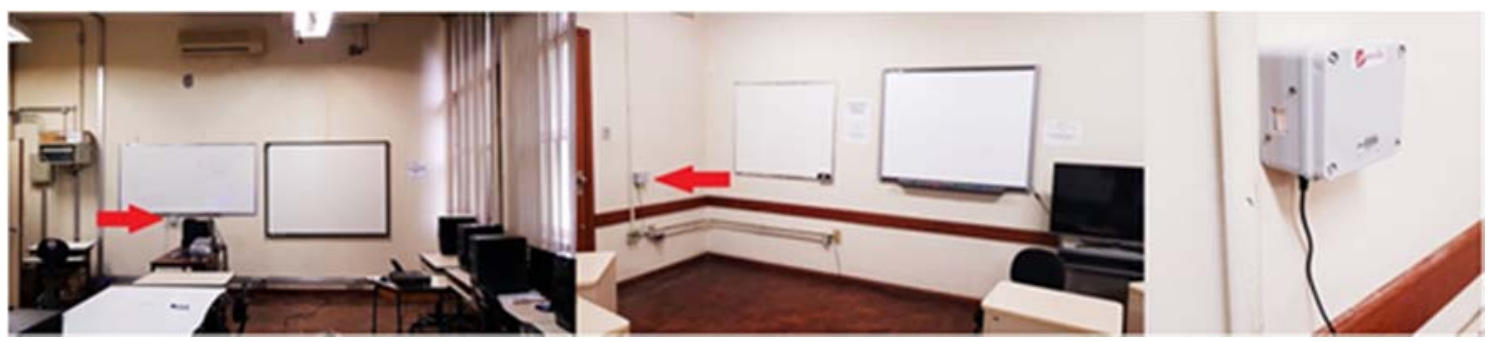

Figura 15 - Sensores de qualidade de ar no CINTED

O sistema ALERTA produz resultados tal como o ilustrado na figura 16 que mostra a variação da concentração de $\mathrm{CO}_{2}$ que tem impacto na performance dos estudantes conforme destacado por (Bakó-Biró et. al. 2012).

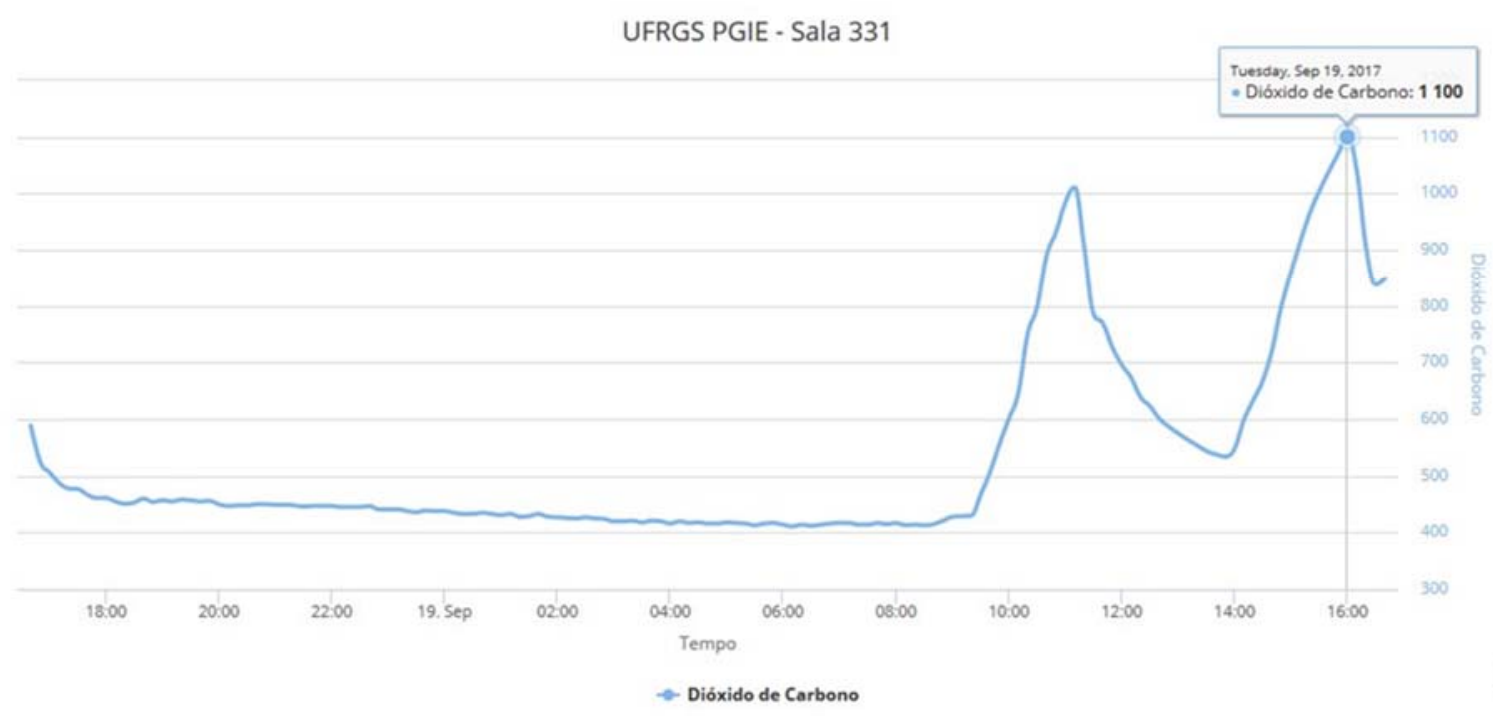

Figura 16 - Resultados da medição da qualidade do ar

\section{Laboratórios virtuais usando dispositivos móveis}

Um novo projeto foi iniciado em 2018, AVAECIM - Ambiente Virtual de Aprendizagem Experimental em Ciências e Matemática. Ele visa o desenvolvimento de 
melhores condições para o ensino e aprendizagem em Ciências e Matemática com recursos de Mobile Learning e os laboratórios virtuais. Este projeto contempla o desenvolvimento de pequeno aplicativos (apps) usando especialmente o MIT App inventor e a versão nova do Scratch 3.0 que pode ser feita em tablets e usada em celulares. Isto permitirá criar pequenos laboratórios virtuais para ensejar uma aprendizagem experiencial inclusive com possibilidade de que os próprios alunos e professores (sem formação em computação) construam seus próprios laboratórios.

\section{Conclusões}

Como considerações finais cabe então destacar a importância do uso de laboratório, especialmente no ensino de Ciências e Matemática. Face à dificuldade em conseguir a disponibilização de laboratórios reais surge a solução dos laboratórios virtuais como solução paliativa. Os laboratórios virtuais naturalmente tem limitações em relação aos laboratórios reais mas com um bom projeto, e uma simulação suficientemente realista com boa dose de interatividade, com objetos que tenham comportamento dinâmico, em função das ações comandadas pelos usuários sobre eles (cliques, proximidade etc...) . Este tipo de solução possibilita que o aluno tenha a chance de realizar a experiência em casa e vir para a sala de aula para discutir seus achados, avaliar a experiência fazendo uma análise crítica de forma colaborativa com os colegas e professor.

O mapa conceitual na figura 18 resume os aspectos relevantes considerados no projeto de laboratório virtual para ensejar ensino e aprendizagem especialmente na Área de Ciências.

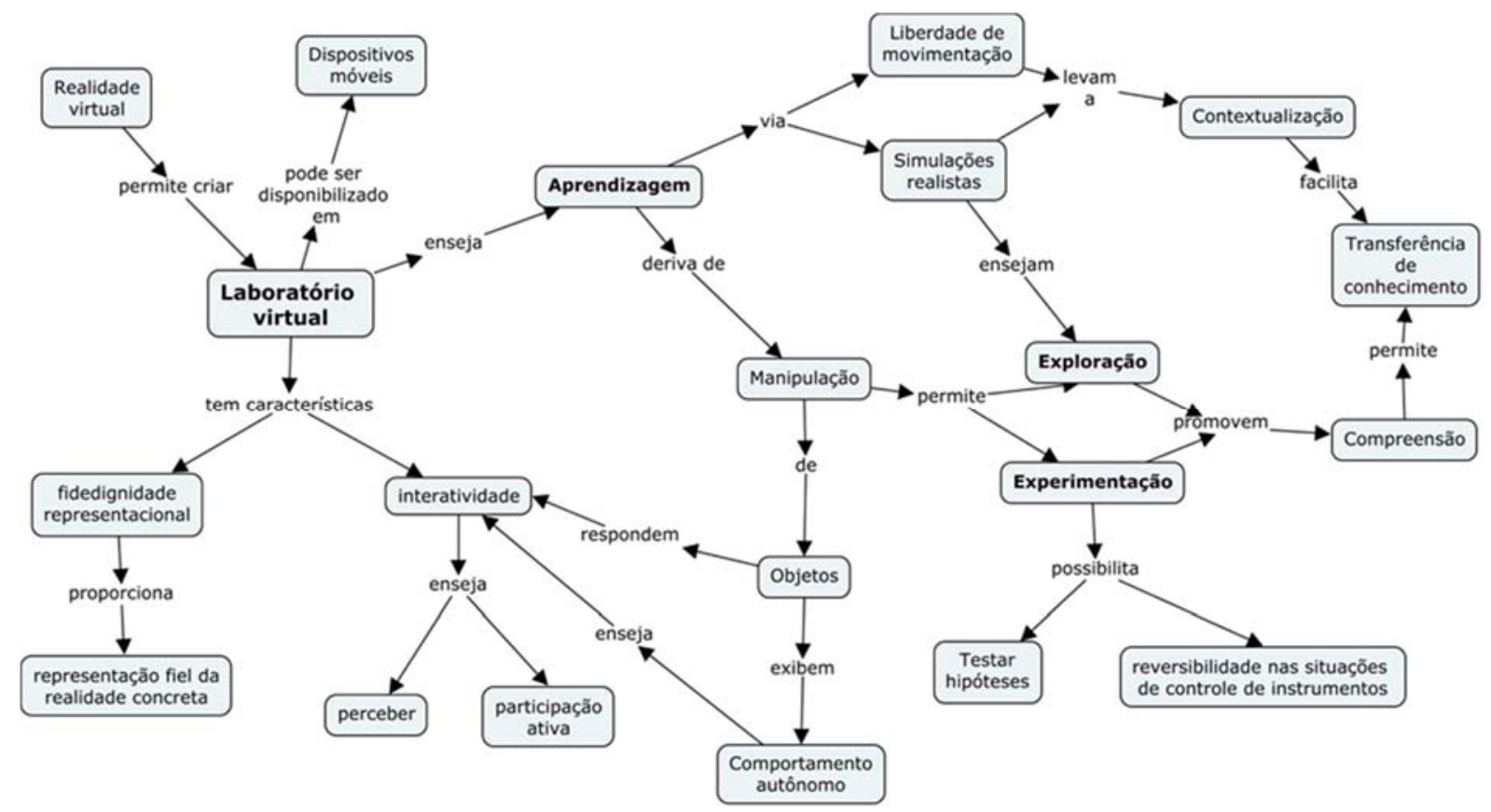

Figura 18: Aspectos relevantes no projeto de um laboratório virtual

Busca-se com este tipo de recurso, promover uma aprendizagem ativa baseada em problemas tal como sugerido por (Antunes et al 2019) e que seja capaz de valorizar o papel ativo do aluno na construção de seu conhecimento e da necessidade em superar a tradicional aula expositiva, cuja finalidade seja apenas a reprodução e a memorização do conteúdo de ensino (Leite 2018).

É necessário planejar e ensejar interações de aprendizagem a serem realizadas no laboratório virtual capazes de promover o desenvolvimento de pensamento de alto nível. 
Neste sentido, os laboratórios virtuais podem oferecer um contexto em que desafios sejam apresentados e levem a atividades de experimentação visando testar hipóteses e que sejam capazes de promover a necessária reflexão, capaz de exercitar e instigar atividades de pensamento de alto nível.

\section{Referências}

ALICE. A.L.I.C.E. A.I Foundation. 2019 . Disponível em https://www.chatbots.org/chatbot/a.1.i.c.e/

Antunes, Jeferson; Nascimento. Verônica; Queiroz, Zuleide. Metodologias ativas na educação: problemas, projetos e cooperação na realidade educativa. Informática na Educação: teoria \& prática, Porto Alegre, v. 22, n. 1, p. 111-127, jan./abr. 2019.

AVATAR - Projeto AVATAR http://www.ufrgs.br/avatar

Bakó-Biró, Z., Clements-Croome, D. J., Kochhar, N., Awbi, H. B., \& Williams, M. J. (2012). Ventilation rates in schools and pupils' performance. Building and Environment, 48, 215-223.

Burke, Jeffrey et al. (2006). Participatory sensing. Center for Embedded Network Sensing. UCLA: Center for Embedded Network Sensing. Retrieved from: http://escholarship.org/uc/item/19h777qd

Conlon, T. PILOT: The Language and how to Use it Including Apple PILOT and SuperPILOT. 1984. Prentice-Hall International.

Cummings, William. The Institutions of Education: a comparative study of educational development in six core nations. Symposium Books. Cambridge University Press.

Didcot Oxford-UK. 2003.

Dede, Chris. Clarke-Midura, Jody. Metcalf, Shari. Virtual Worlds for Education: River City and EcoMUVE. 2009. MIT6 International Conference.

Gardner Group. Gartner Hype Cycle for Emerging Technologies, 2018. Disponível em https://www.fourquadrant.com/gartner-hype-cycles-magic-quadrants/

Herpich, Fabrício; Guarese, Renan; Tarouco, Liane Comparative Analysis of Augmented Reality Frameworks Aimed at the Development of Educational Applications. CREATIVE EDUCATION. , v.08, p.1433 - 1451, 2017.

Klein, Suelena Porto. Leonel, Neron Arruda. Instrução e avaliação assistida por computador : técnicas e aplicações. In: Congresso Nacional de Informática. Anais. São Paulo : Sucesu, 1981. p. 26-34

LEITE, B. S.. Aprendizagem tecnológica ativa. Revista Internacional de Educação Superior. Rev. Inter. Educ. Sup.Campinas, SPv.4n.3p.580-609set./dez. 2018 DOI:10.20396/riesup.v4i3.8652160

MIT. Massachusetts Institute of Technology. MIT App Inventor. 2019. Disponível em https://appinventor.mit.edu/

MIT. Massachusetts Institute of Technology. Scratch. Lifelong Kindergarten Group do MIT Media Lab. 2009. Disponível em https://scratch.mit.edu/

OpenSimulator. OpenSim Wiki Page. 2019 Disponível em http://opensimulator.org/wiki/Main_Page 
Resnick, Mitcher. Scratch that. Princeton alumni weekly. October 25, 2017 Disponível em http://web.media.mit.edu/ mres/press/PAW-Scratch.pdf p 30-34

Santarosa, Lucila. EDUCOM da Faculdade de Educação da Universidade Federal do Rio Grande do Sul. In: Projeto EDUCOIM - realizaççoes e produtos. Org.: Pedro Andrade. MEC/OEA. Brasília 1993. p 185-218.

Sgobbi, F., Tarouco, L., Reategui, E. (2017). The pedagogical use of the Internet of things as a lever of behavior change in obese individuals 2017 IEEE International Conference on Internet of Things (iThings). Exeter-UK.

SGOBBI, F. S.; Tarouco, L.M.R.; Reategui, E Mundo virtual e Internet das Coisas para 3D motivar mudança de comportamento saudável. REVISTA IBEROAMERICANA DE TECNOLOGIA EN EDUCACIÓN Y EDUCACIÓN EN TECNOLOGÍA (EN LÍNEA). , v.19, p.7 - 15, 2017.

Tarouco, Liane. Programando para crianças. Micro Sistemas. 1981. São Paulo. p 34-35.

Tarouco, Liane, Silva, Patrícia. Herpich, Fabrício. Cognição e aprendizagem em Mundo Virtual Imersivo. 2018. Projeto AVATAR. CINTED/UFRGS. Disponível em http://penta3.ufrgs.br/AVATAR/Livro/AVATAR-Cogni\%C3\%A7\%C3\%A3oAprendizagem-MundoVirtual-2018.pdf

Tarouco, L.M.R.; Boesing, I. J.; Barone, Dante; Rosa, Gilberto. Internet das Coisas na Educação trajetória para um campus inteligente In: Congresso Brasileiro de Informática na Educação, 2017, Recife-PE. Porto Alegre - RS: Sociedade Brasileira de Computação, 2017. v.1. p.1220 - 1231 